\title{
Arduino based Dual Axis Smart Solar Tracker
}

\author{
Jyoti Mishra, Ritula Thakur, Alok Deep
}

\author{
Department of Electrical Engineering, NITTTR, Chandigarh, India
}

\begin{abstract}
Solar energy is rapidly advancing as an important means of renewable energy resource. It is radiant light and heat from the Sun that is harnessed using a range of ever-evolving technologies such as solar heating, photovoltaic, solar thermal energy, solar architecture, molten salt power plants and artificial photosynthesis. Trackers direct solar panels or modules toward the sun. These devices change their orientation throughout the day to follow the sun's path to maximize energy capture. The use of solar trackers can increase electricity production by around a third, and some claim by as much as $40 \%$ in some regions, compared with modules at a fixed angle. In any solar application, the conversion efficiency is improved when the modules are continually adjusted to the optimum angle as the sun traverses the sky. This paper presents the designing of a solar tracking system which is based on Arduino UNO and which provides movement of solar panel in the direction of maximum sun light incident. As a result of which we get more efficient system which is compact, low cost as well as easy to use.
\end{abstract}

Keywords- Arduino UNO, Bluetooth module, Solar Panel, Servo Motor.

\section{INTRODUCTION}

Sun is an abundant source of energy and this solar energy can be harnesses successfully using solar photovoltaic cells and photovoltaic effect to convert energy into electrical energy. But the conversion efficiency of a normal PV cell is low. One of the main reason for this is that the output of PV cell is dependent directly on the light intensity and with the position of sun in the sky changing continuously from time to time, the absorption efficiency of an immobile solar panel would be significantly less at certain time day and year, for the solar photovoltaic cells are maximum productive when they are perpendicular to the sun and less productive otherwise. So to maximize the energy generation and improve the efficiency solar trackers are required.

The solar tracker also provided lucrative solution for third world countries to integrate it into their solar system with a comparatively low cost through software based solution. The study revealed that use of stepper motor enables accurate tracking of sun and LDR resistors used to determine the solar light intensity [1]. Researchers concluded that embedding the tracking system with solar panel can response accurate and applicable to meet the power demands at different operational conditions.

A solar tracking system designed with microcontroller and LDR's that actively track the sun and change its position accordingly to maximize the energy output. The LDR incorporated on solar panel helps to detect sunlight which in turn moves the panel accordingly [2] .The solar tracker described a more improved way to maximize the power consumption by solar panel from sun by just rotating the solar panel according to sun's position. By comparing the results it was discovered that direct beam of sun helps in generating energy than it is produced when solar panel is kept fixed. The studied have shown that efficiency of solar panels can be increased to a great extent if the solar panels continuously rotate in the direction of sun. Microcontroller and an arrangement of LDR sensors can be used for the purpose of tracking the sun [3]. But the system was less efficient because of the low sensitivity and disturbance of light dependent resistors. The mechanism of solar tracking was implemented by the use of image processing software which combines the effect of sensors and processed image of sun and controls the solar panel accordingly. A new mechanical structure for solar trackers which implemented two stepper motors for free rotation on $\mathrm{X}$ and $\mathrm{Y}$ axis [4]. The rotation was intelligently controlled by a pre-programmed $2 \mathrm{~K}$ microcontroller device PIC 18F4560 which provides simple programming strategy through $\mathrm{C}$ language. The designed algorithm was based on the measurement of intensity of solar radiation which was captured by an ultra violet sensitive device known as Pyranometer. The system had been tested and the results show very significant impact on the mechanical design, controlling algorithm and also the cost of the development.

\section{BLOCK DIAGRAM DESCRIPTION}

The main aim of the proposed system is to develop a cost effective instrument using an Arduino Microcontroller based solar tracking system using Bluetooth module for detection of voltage and getting the result in android app. Block diagram of complete system is shown in Fig. 1 below which consists of power supply, Arduino Uno, LDR sensor, servo motor, and solar panel. 


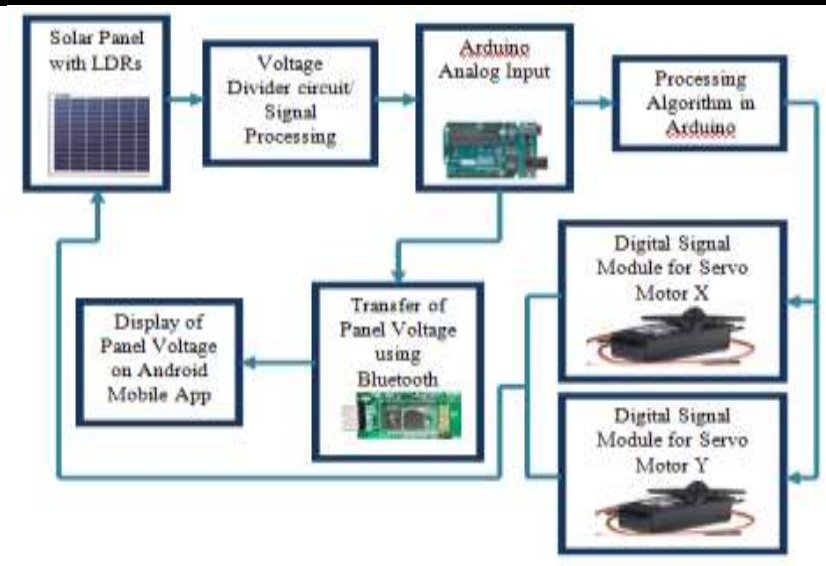

Fig. 1: Block diagram of System

\section{A. HC-05 Bluetooth to Serial Port Module}

The HC05 Bluetooth Module can be used in a Master or Slave configuration, making it a great solution for wireless communication. It can be used simply for a serial port replacement to establish connection between MCU and GPS, PC to embedded project. The HC05 module has 6 pins Vcc, GND, Tx, Rx, Key and LED. It comes preprogrammed as a slave, so there is no need to connect the key pin, unless it is needed to be chnaged to master mode. The major difference between Master and Slave modes is that, in Slave mode the Bluetooth module cannot initiate a connection; it can however accept incoming connections.

Table.1: Pin Description of HC05 Bluetooth Module

\begin{tabular}{|c|c|}
\hline PIN NO. & CONFIGURATION \\
\hline Pin 1 & $\begin{array}{r}\text { STATE: NC (No } \\
\text { Connection) }\end{array}$ \\
\hline Pin 2 & Rx: Tx of Microcontroller \\
\hline Pin 3 & Tx: Rx of Microcontroller \\
\hline Pin 4 & GND: Ground \\
\hline Pin 5 & VCC: $+5 \mathrm{~V}$ \\
\hline Pin 6 & EN: NC (No Connection) \\
\hline
\end{tabular}

After the connection is established the Bluetooth module can transmit and recieve data regradless of the mode it is running in. If we use mobile phone to connect to the Bluetooth module, we can simply use it in the Slave mode. . The module has a factory set pin of " 1234 " which is used while pairing the module to a phone. The HC-05 module can build a connection to the other modules.

\section{B. Over view of Arduino}

Arduino is an open-source electronics prototyping platform, mostly based on small, easy-to-use hardware and software [5-6]. It can affect devices, like lights, motors and other actuators by receiving input from sensor. All the action performed by Arduino is programmed to the microcontroller on the board via Arduino programming language and the Arduino development environment. Arduino projects can be standalone or communicate with other software applications running on a computer and other types of hardware.

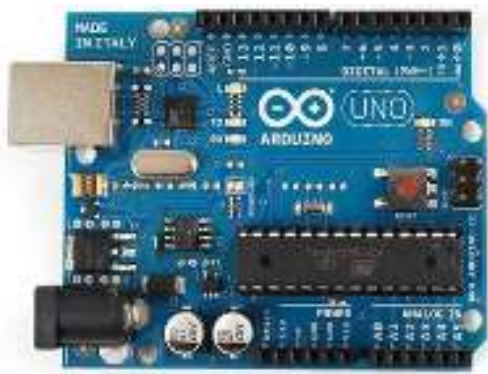

Fig. 2: Arduino Uno Microcontroller Development Board

The Adruino Uno board as shown in Fig. 2. The Table.1 shows the specifications of Arduino Uno microcontroller board.

Table.2: Arduino Uno specifications

\begin{tabular}{|l|c|}
\hline Microcontroller & ATmega328 \\
\hline Operating Voltage & $5 \mathrm{~V}$ \\
\hline $\begin{array}{l}\text { Supply Voltage } \\
\text { (recommended) }\end{array}$ & $7-12 \mathrm{~V}$ \\
\hline $\begin{array}{l}\text { Maximum supply Voltage } \\
\text { (not recommended) }\end{array}$ & $20 \mathrm{~V}$ \\
\hline Digital I/O Pins & $\begin{array}{c}\text { 14(of which 6 provide } \\
\text { PWM output) }\end{array}$ \\
\hline Analog Input Pins & 6 \\
\hline DC Current per I/O Pin & $40 \mathrm{~mA}$ \\
\hline DC Current for 3.3V Pin & $50 \mathrm{~mA}$ \\
\hline Flash Memory & $\begin{array}{c}32 \mathrm{~KB} \text { of which } 0.5 \mathrm{~KB} \\
\text { used by boot loader }\end{array}$ \\
\hline SRAM & $2 \mathrm{~KB}$ \\
\hline EEPROM & $1 \mathrm{~KB}$ \\
\hline Clock Speed & $16 \mathrm{MHz}$ \\
\hline
\end{tabular}

\section{FLOWCHART OF PROCESS}

The given flow chart shows the order of steps taken in the process for designing and working of solar tracking system. The system is designed in order to respond to the sunlight incident on the solar panel, according to which the movement of solar panel is done. Working of system is controlled by arduino microcontroller. 


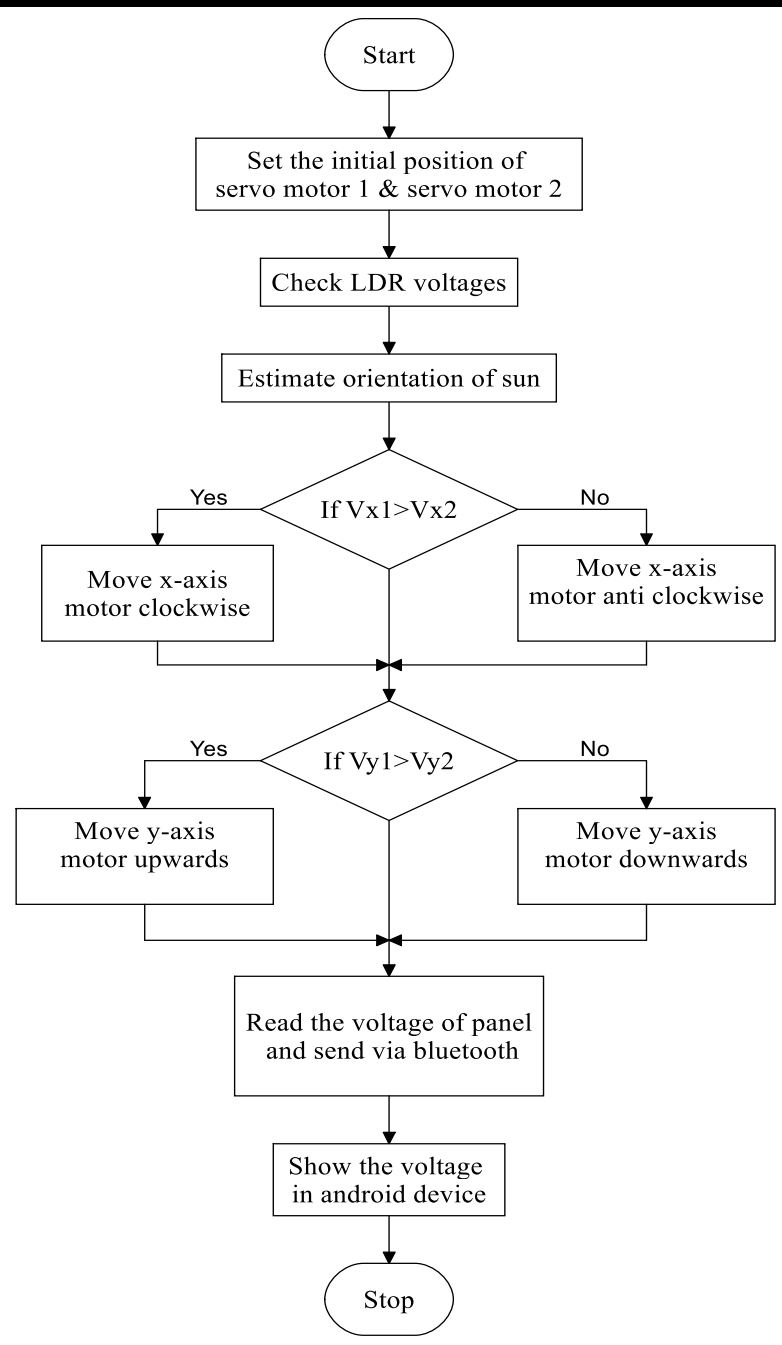

Fig. 3: Flow Chart of Process

From the flow chart it can be seen that initially the position of both the motors is being set after that the voltage of LDR is checked. After this process the orientation of sun is being estimated, according to which the sunlight falls on the LDR. There are four LDR used on four sides of solar panel at which sunlight falls, out of these two work for horizontal and two works for vertical movement of panel. The voltages of $\mathrm{x}$ axis sensors are compared as well as $y$ axis sensors, as a result of which the panel moves in clockwise/anticlockwise or upward/downward direction. The direction of movement of panel is always in the direction of maximum sun light. So, the solar tracker provides higher efficiency.

\section{HARDWARE IMPLEMENTATION}

Complete system assembly of Solar is shown in Fig. 4 and 5. The system consists of Power supply unit for whole system, Arduino UNO board, HC05 Bluetooth module, two servo motors, solar panel, four LDR sensors fixed on on solar panel and voltage divider circuitry.

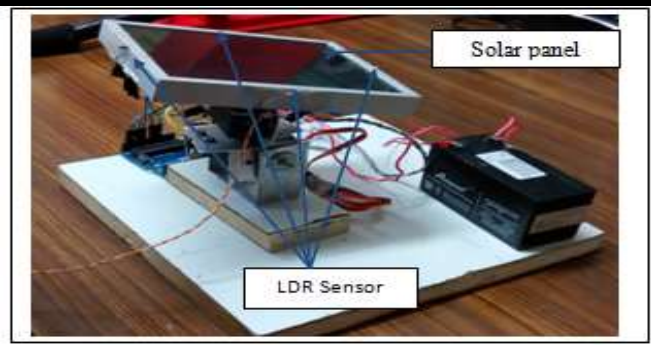

Fig. 4: Complete Hardware assembly

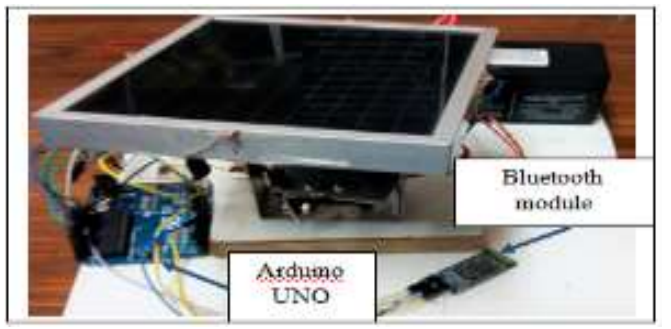

Fig. 5: Hardware Assembly with Bluetooth Module

\section{RESULTS AND DISCUSSION}

After designing, developing and implementing of the smart solar tracker system for voltage measurement, improvement of solar panel efficiency, compact and low power system is successfully done. System is tested at different times of a day in presence of varying orientation of sun so that it is able to detect the incident light in different conditions. The output is taken with the help of panel movement according to maximum efficiency. The developed system provides results and output in android device through transmission from the controller and we get real time measurement on the mobile app. The output obtained in mobile app is shown below in Fig. 6 .
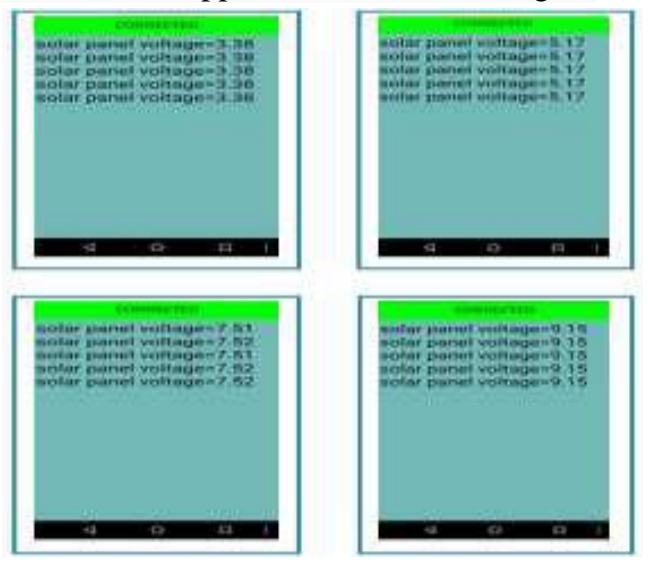

Fig. 6: Real Time Values of Solar Panel Voltage in Mobile App

The readings of solar panel were recorded with and without tracking of system and in both the conditions different output is obtained. The obtained readings are given in Table 3. 
Table.3: Comparison of Panel Voltage with and without Tracking

\begin{tabular}{|c|c|c|}
\hline \multirow{2}{*}{ TIME } & \multicolumn{2}{|c|}{ SOLAR PANEL VOLTAGE } \\
\cline { 2 - 3 } & $\begin{array}{c}\text { WITHOUT } \\
\text { TRACKING }\end{array}$ & $\begin{array}{c}\text { WITH } \\
\text { TRACKING }\end{array}$ \\
\hline $08: 00 \mathrm{am}$ & $3.62 \mathrm{~V}$ & $5.78 \mathrm{~V}$ \\
\hline $10: 00 \mathrm{am}$ & $5.10 \mathrm{~V}$ & $7.08 \mathrm{~V}$ \\
\hline $12: 00 \mathrm{pm}$ & $7.26 \mathrm{~V}$ & $8.98 \mathrm{~V}$ \\
\hline $01: 00 \mathrm{pm}$ & $8.42 \mathrm{~V}$ & $9.62 \mathrm{~V}$ \\
\hline $02: 00 \mathrm{pm}$ & $8.15 \mathrm{~V}$ & $9.58 \mathrm{~V}$ \\
\hline $04: 00 \mathrm{pm}$ & $5.42 \mathrm{~V}$ & $8.23 \mathrm{~V}$ \\
\hline $06: 00 \mathrm{pm}$ & $3.24 \mathrm{~V}$ & $6.27 \mathrm{~V}$ \\
\hline $08: 00 \mathrm{pm}$ & $0.12 \mathrm{~V}$ & $0.38 \mathrm{~V}$ \\
\hline
\end{tabular}

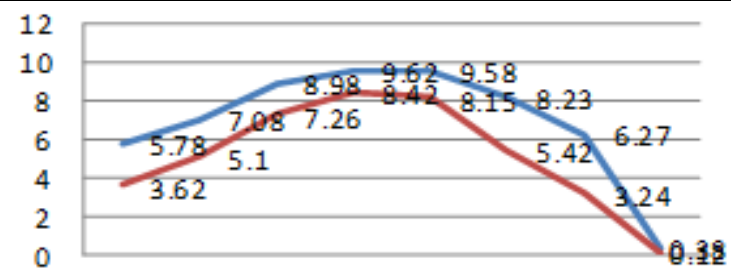

8:00 10:0012:00 1:00 2:00 4:00 6:00 8:00 TIME (hour)

Fig. 7: Graphical Representation of Data

\section{CONCLUSION}

The aim of this project was to design a dual axis tracking system which can sense the incident solar light on the panel and move it in the direction of maximum solar light incident. Further the advantages and disadvantages were also studied. The disadvantages were the challenges that had to be overcome. From this study the main conclusions are:

i. Proposed system is low cost and compact as compared to the other tracking systems in use for same application.

ii. It is very easy to program and modify because it is Arduino based and no external programmer is required.

iii. The designed system is easy to use and provides better efficiency of the panel.

iv. In the developed system real time data is retrieved on the android device.

\section{REFERENCES}

[1] Khyati vyas, Dr. Sudhir Jain, Dr. Sunil Joshi, " A Review on an Automatic Solar tracking System", International Journal of Computer Applications, 2014.

[2] Priyanjan Sharma, Nitesh Malhotra, "Solar Tracking System Using Microcontroller", Proceedings of 1st International Conference on Non Conventional Energy, pp. 77-79, January 16-17, 2014
[3] Hanif Ali Sohag, Mahmudul Hasan, Mahmuda Khatun, Mohiuddin Ahmad, "An accurate and efficient solar tracking system using image processing and LDR sensor", 2nd International Conference on Electrical Information and Communication Technologies, pp. 522-527, 2015.

[4] M. Amir Abas , M. Hilmi Fadzil S, Samsudin A.Kadir, A. Khusairy Azim, "Improved Structure of Solar Tracker with Microcontroller based Control "Second International Conference on Advances in Computing, Control, and Telecommunication Technologies, pp. 55-59, 2010.

[5] Dipti Bawa, C.Y. Patil, "Fuzzy control based solar tracker using Arduino Uno "International Journal of Engineering and Innovative Technology, Vol. 2, No. 12, pp. 179-187, June 2013.

[6] Radhika Grover, Shoba Krishnan, Terry Shoup, Maryam hanbaghi, "A Competition-Based Approach for Undergraduate Mechatronics Education Using the Arduino Platform", 4 ${ }^{\text {th }}$ Interdisciplinary Engineering Design Education Conference (IEDEC), Santa Clara, CA, pp 78-83, Mar 2014.

[7] Syed Arsalan, "Sun Tracking System with Microcontroller 8051", International Journal of Scientific \& Engineering Research, Vol. 4, No. 6,pp. 2998-3001, June 2013.

[8] Soumya Das , Pradip Kumar Sadhu, Nitai Pal , Suprotim Mukherjee, "Single Axis Automatic Solar Tracking System Using Microcontroller", Vol. 12, No. 12, pp. 8028-8032, December 2014.

[9] Tarlochan Kaur, Shraiya Mahajan, Shilpa Verma, Priyanka, Jaimala Gambhir, "Arduino Based Low Cost Dual Axis Solar Tracker", IEEE International conference on Power Electronics, Intelligent control and Energy Systems, pp. 1-5, 2016.

[10] Mukul Goyal, Manohar H, Ankit Raj, Kundan Kumar, "Smart Solar Tracking System", International Journal of Engineering Research \& Technology, Vol. 4, No. 2, pp. 367-369, February2015 . 